\title{
A LEITURA NO VESTIBULAR E A PRODUÇÃO DE CERTOS DISCURSOS SOBRE O BRASIL
}

Dr. ${ }^{\text {a }}$ Erislane Rodrigues Ribeiro

Curso de Letras - Campus Catalão, da Universidade Federal de Goiás

\section{$\underline{\text { RESUMO }}$}

Com base nos conceitos de dialogismo e heterogeneidade discursiva, formulados por Bakhtin (2000) e Authier-Revuz (2004), respectivamente, e na tese de que há leituras erradas, conforme Possenti (1999) e (2001), neste artigo, analisamos noventa enunciados obtidos de respostas erradas de vestibulandos à questão 7 da prova discursiva de Língua Portuguesa do Processo Seletivo 2003 da UFG. Nosso objetivo é demonstrar que a leitura errada realizada pelos candidatos, às vezes, funciona como ponto de partida para o estabelecimento de um estreito diálogo entre os discursos por eles defendidos com discursos sobre as belezas e/ou as mazelas do Brasil, veiculados, cotidianamente, em diversas instâncias, inclusive pelo Senso Comum.

PALAVRAS-CHAVE: Leitura, Vestibular, dialogismo, heterogeneidade, discursos, Brasil.

\section{ABSTRACT}

Based on the concepts of dialogism and discursive heterogeneity, expressed by Bakhtin (2000) and Authier-Revuz (2004), respectively, and the thesis that there is erroneous readings, as Possenti (1999) and (2001), in this article, we analyze ninety excerpts from vestibulandos of wrong answers to question 7 of the discursive test of Portuguese of Vestibular 2003 of UFG. Our goal is to demonstrate that the misreading held by applicants, sometimes works as a starting point for establishing a close dialogue between the discourses they held with discourses about the beauty and/ or the problems of Brazil, running, daily, in multiple domains, including the Common Sense.

KEY-WORDS: Reading, Vestibular, dialogism, heterogeneity, discourses, Brazil.

\section{Introdução}

Partindo do pressuposto bakhtiniano de que todo texto é constituído dialogicamente, vários pesquisadores, ao realizarem suas análises, costumam ressaltar a heterogeneidade como algo que contribui para a qualidade da leitura e da escrita de texto. Neste trabalho, pretendemos mostrar como a leitura equivocada também é marcada pela heterogeneidade discursiva. Procuramos explicitar a emergência de alguns discursos, os quais, veiculados pelos vestibulandos ao responderem certas questões, levam-nos ao erro, pois revelam leituras equivocadas que os mesmos realizam.

O córpus desta pesquisa limita-se a noventa enunciados obtidos com a leitura de respostas equivocadas elaboradas para a questão 7 da prova 
discursiva de língua portuguesa do Processo Seletivo 2003 (PS 2003). Com relação à fundamentação teórica, sobre o conceito de heterogeneidade discursiva, central nessa pesquisa, discorremos a partir da retomada, em particular, do texto de Bakhtin (2000) e de Authier-Revuz (2004). Em relação à leitura especificamente, utilizamos a noção de leitura errada apresentada por Possenti (1999) e (2001), pois defendemos que os discursos que constituem as respostas erradas em análise resultam de equívocos de leitura por parte dos candidatos.

Nosso texto organiza-se da seguinte forma. Primeiramente, localizamos o conceito de dialogismo bakhtiniano como ponto de partida para a teoria da heterogeneidade proposta por Authier-Revuz (2004); em seguida, discorremos sobre a ênfase dada a cada instância da leitura (autor, texto, leitor) ao longo da História e defendemos a tese de que a leitura errada existe; a seguir, apresentamos e comentamos brevemente a questão 7 do PS 2003; depois, passamos a analisar enunciados elaborados por vestibulandos como respostas à questão 7 do PS 2003, os quais não respondem as questões propostas. Aqui, chamamos a atenção para a presença da heterogeneidade constitutiva, pois uma série de discursos que remete ao comportamento de políticos, às riquezas e mazelas do Brasil, às mulheres brasileiras e à exploração sexual podem ser observados nas respostas erradas produzidas pelos candidatos. Por fim, apresentamos nossas considerações finais e as referências bibliográficas.

$-$

\section{Sobre os conceitos de dialogismo e heterogeneidade discursiva}

Segundo Possenti, ([2003?], p. 1), "Sob diversos nomes - polifonia, dialogismo, heterogeneidade, intertextualidade - cada um implicando algum viés específico, como se sabe, o interdiscurso reina soberano há algum tempo". Em nosso trabalho, assumimos os vieses que os nomes dialogismo e heterogeneidade implicam, adotando o conceito de dialogismo, proveniente do sentido amplo atribuído por Bakhtin (1995) ao termo diálogo. Para o filósofo russo,

o diálogo, no sentido estrito do termo não constitui, é claro, senão uma das formas, é verdade que das mais importantes, da interação verbal. Mas pode-se compreender a palavra "diálogo" num sentido amplo, isto é, não apenas como a comunicação em voz alta, de pessoas colocadas face a face, mas toda comunicação verbal, de qualquer tipo que seja. (BAKHTIN, 1995, p. 123).

Por questões metodológicas, distinguimos essas duas maneiras de compreender o diálogo (entre interlocutores e entre discursos), as quais são traduzidas por Brandão (1997, p. 286) do seguinte modo: “além do outro explicitado na figura do destinatário, temos ainda o outro, na figura do interdiscurso, do diálogo que todo texto trava com outros textos". 
Tratamos, aqui, da primeira noção de dialogismo, a que Bakhtin chama de interação verbal. Para ele, a categoria básica da concepção de linguagem é a interação verbal cuja realidade fundamental é seu caráter dialógico, condição de constituição do sentido. Ele afirma que se pode compreender a palavra "diálogo" num sentido mais amplo, exemplificando sua tese ao dizer que o livro, por exemplo, é "um ato de fala impresso", que "constitui igualmente um elemento da comunicação verbal". Para ele, portanto, a enunciação, "por mais significativa e completa que seja, constitui apenas uma fração de uma corrente de comunicação verbal ininterrupta (concernente à vida cotidiana, à literatura, ao conhecimento, à política, etc.)" (BAKHTIN, 1995, p. 123).

Fundamentando sua teoria nas idéias de Bakhtin sobre o dialogismo, Authier-Revuz (2004) privilegiou a questão da "heterogeneidade do discurso", desenvolvendo uma oposição conceitual muito utilizada pelos lingüistas. Como ressalta Maingueneau $(2005$, p. 33), “quando os lingüistas precisam encarar a heterogeneidade enunciativa, são levados a distinguir duas formas de presença do "Outro" no discurso: a heterogeneidade "mostrada" e a heterogeneidade "constitutiva"”. Na verdade, o conceito de heterogeneidade proposto por Authier-Revuz (2004) "é uma maneira de precisar teoricamente o conceito bakhtiniano de dialogismo" (FIORIN, 1997, p. 230).

Na citação a seguir, as considerações de Bakhtin (2000) permitem-nos reconhecê-lo como fonte para o que, mais tarde, Authier-Revuz (2004) denominou "heterogeneidade mostrada". Essa forma de heterogeneidade permite que se apreendam seqüências lingüísticas em que o outro se mostra. Exemplificam-se, abaixo, o discurso direto, a paráfrase, a entonação, além de outras formas da heterogeneidade mostrada.

o enunciado é repleto de reações-respostas a outros enunciados numa dada esfera da comunicação verbal. Estas reações assumem formas variáveis: podemos introduzir diretamente o enunciado alheio no contexto do nosso próprio enunciado, podemos introduzir-lhe apenas palavras isoladas ou orações que então figuram nele a título de representantes de enunciados completos. [...] também é possível, num grau variável, parafrasear o enunciado do outro depois de repensálo, ou simplesmente referir-se a ele como a opiniões bem conhecidas de um parceiro discursivo; é possível pressupô-lo explicitamente; nossa reação resposta também pode refletir-se unicamente na expressão de nossa própria fala - na seleção dos recursos lingüísticos e de entonações, determinados não pelo objeto de nosso discurso e sim pelo enunciado do outro acerca do mesmo objeto. (BAKHTIN, $\underline{2000, \text { p. 316) }}$

Em seu trabalho, Authier-Revuz (2004) privilegia a análise dessas formas de heterogeneidade mostrada que acusam a presença do outro (o discurso relatado direto e o discurso relatado indireto, as formas de conotação autonímica, o discurso indireto livre, a ironia, a imitação etc.) e defende que

a través dessas marcas, designando o outro localizadamente, o sujeito empenha-se em fortalecer o estatuto do um. É nesse sentido que a heterogeneidade mostrada pode ser considerada como um modo de denegação no discurso da heterogeneidade constitutiva que depende do outro no um. (AUTHIER-REVUZ, 2004, p. 75). 
A leitura de outros trechos em Bakhtin (2000, p. 317) revela-nos sua preocupação principal, a saber, a defesa de que o diálogo é constitutivo de todo e qualquer enunciado. Segundo o autor,

por mais monológico que seja um enunciado (uma obra científica ou filosófica, por exemplo), por mais que se concentre no seu objeto, ele não pode deixar de ser também, em certo grau, uma resposta ao que já foi dito sobre o mesmo objeto, sobre o mesmo problema [...]. (BAKHTIN, 2000, p. 317).

A partir dessa noção bakhtiniana, Authier-Revuz (2004) conceitua a heterogeneidade constitutiva, opondo-a à heterogeneidade mostrada. Segundo a autora, "Nenhuma palavra é 'neutra', mas inevitavelmente 'carregada', 'ocupada', 'habitada', 'atravessada' pelos discursos nos quais 'viveu sua existência socialmente sustentada'”, em outras palavras, "as palavras são, sempre e inevitavelmente, 'as palavras dos outros'” (AUTHIER-REVUZ, 1990, p. 26-27).

E enquanto a heterogeneidade mostrada inscreve o outro no fio do discurso, a constitutiva não revela o outro e é concebida no nível do inconsciente. Desse modo, além de retomar a temática do dialogismo de Bakhtin, em sua concepção da heterogeneidade constitutiva, Authier-Revuz (2004) lida com a relação do sujeito com a linguagem através de uma abordagem psicanalítica. A autora mostra como a psicanálise questiona a unicidade significante da concepção homogeneizadora da discursividade. Nas palavras de Brait (2001),

Authier promove a compatibilidade, a cumplicidade, de certa forma também inalienável, entre o "outro" bakhtiniano, concebido numa dimensão ideológica constitutiva da linguagem, e que significa tanto o interlocutor quanto os outros discursos constitutivos de qualquer discurso, e o "outro" lacaniano, concebido, na dimensão do inconsciente, como um desdobramento do mesmo. (BRAIT, 2001, p. 17).

Com base na análise das marcas explícitas da heterogeneidade mostrada, articulada à heterogeneidade constitutiva da linguagem, Authier-Revuz (2004) percebe, segundo Brandão (1997, p. 56) "uma espécie de negociação entre as duas formas de heterogeneidade". O falante, diante da impossibilidade de fugir da heterogeneidade constitutiva a que está submetido todo discurso, quando demarca a presença do outro, utilizando marcas da heterogeneidade mostrada, revela um desejo de dominância. "Isto é, movido pela ilusão do centro, por um processo de denegação em que localiza o outro e delimita o seu lugar, o falante pontua o seu discurso, numa tentativa de 'circunscrever e afirmar o um'” (BRANDÃO, 1997, p. 57).

\section{Sobre leitura}


Historicamente, acerca da leitura, três posições se sucederam. A primeira delas, anterior ao surgimento da lingüística moderna, sustentava a tese de que ler é tentar descobrir quais são as intenções, o pensamento do autor de um texto. Nesse período, predominou a instância do autor.

\begin{abstract}
Foram os tempos das tentativas de situar o texto em seu contexto específico, levando-se em conta o sentido das palavras na época de seu uso e vendo em qualquer uso não transparente ou não regular da linguagem uma manobra que denunciava alguma característica pessoal do autor do texto, que por ela se revelava. (POSSENTI, 1985, p. 9).
\end{abstract}

A segunda, fundada sobre os preceitos da lingüística estruturalista, negou o autor e deu ao texto o estatuto de determinante da leitura realizada pelo leitor, como se ela fosse um produto totalmente inscrito na materialidade textual. Segundo Possenti, (1985, p. 9), sob a égide dessa concepção de leitura, na teoria literária, por exemplo, "viveu-se um período relativamente longo de tentativa de abandono do autor e das circunstâncias, para apreender as invariantes dos textos. O texto fala por sua estrutura, não pela boca de seu autor".

Descobriu-se, no entanto, que o texto é impotente "para ser o árbitro da pendenga pelo sentido" Com isso, decidiu-se "promover duas alterações táticas importantes: a primeira foi deslocar o centro da questão para o leitor; a segunda foi abandonar a exigência do sentido correto". (POSSENTI, 1999, p. 171).

Surge, então, a posição segundo a qual o leitor é quem comanda o processo de leitura. Quanto ao texto, “[...] seria de ordem tal que a idéia da apreensão de seu sentido seria uma ilusão, um equívoco". Os vários sentidos que o texto pode ter em função de leituras singulares realizadas por diferentes interlocutores, ou mesmo leituras diferentes feitas por um mesmo leitor em momentos distintos levaram à idéia de que "o texto só existe no momento da leitura". (POSSENTI, 1985, p. 9-10).

A primeira posição --- ao defender que há um sentido original inscrito pelo autor no texto ---, e a segunda --- que vê o texto como um sistema a ser decodificado pelo leitor ---, fundam-se como propostas de fechamento da leitura. A última, ao contrário, quando defende que o texto é aberto, propõe o inverso, quer dizer, apresenta o texto como objeto de várias leituras, dando, assim, ao leitor o papel de maior relevância na tríade autor-texto-leitor. É um jogo perigoso: de um lado, monopoliza-se a leitura, interditam-se os movimentos de interpretação, valorizando-se apenas os leitores institucionalmente iniciados e autorizados; de outro, aceita-se qualquer leitura como correta, como se as palavras do outro não tivessem nenhuma relevância.

As posições acima descritas, pensadas em relação ao trabalho com a leitura na escola, suscitam inquietação. Num texto em que analisa o 
enfraquecimento da sociedade e da leitura materializada pelo texto, Barzotto (2001) assevera que

[...] o que se verifica com relação à perda de limites na sociedade em geral é a passagem de um conhecimento dogmático e autoritário, que promove a submissão e a adaptação, a um desmonte do conhecimento produzido, desconsiderando o trabalho dos sujeitos que os produziram, bem como sua própria existência, uma vez que qualquer outro seria considerado do mesmo modo. (BARZOTTO, 2001, p. 247).

Na escola, a uma prática de imposição, em que valia a leitura mediada pelo professor --- tido como autoridade capaz de dizer qual é o sentido pretendido pelo autor ou qual é o sentido inscrito no texto --- opôs-se a liberdade sem limites, como se o texto fosse passível de qualquer interpretação e leitura, o que resultou num quadro tal que nenhuma leitura podia ser considerada errada. Isso acabou se refletindo na prática, pois, nas escolas de primeiro e segundo graus, nas universidades, nos congressos se alguém criticava a leitura realizada por alguém, dizendo estar errada, logo se ouviam comentários como: "é a minha leitura”, "há tantas leituras quanto leitores” etc.

Opondo-se a esse quadro, Possenti (1999) e (2001) defende a posição de que a leitura errada existe. Isso ocorre, segundo o autor, porque "o leitor lê o que é possível para ele ler”. Não por uma questão de competência, porque seja melhor ou pior leitor que outra pessoa, mas porque cada indivíduo "tem uma certa ideologia”. É por isso que a mesma pessoa não é capaz de dar muitos sentidos a um texto. As interpretações "têm a ver com as posições dos leitores" (POSSENTI, 2001, p. 13). Conforme ressalta o autor, “[...] pode haver leitores com enciclopédias, que lhes permitem ler corretamente certos textos e leitores que não conseguem ler certos textos senão de forma equivocada" (POSSENTI, 1999, 174).

Na perspectiva da análise do discurso, Possenti e Barzotto apontam um caminho a seguir. O primeiro afirma que "devemos ser contrários, evidentemente, àqueles que dizem que o sentido do texto é fixo. [...] Mas a liberalidade total não é possível” (POSSENTI, 2001, p. 12). Quanto ao texto, para o autor, deve ser considerado mais importante que o leitor. E Barzotto (1999) pondera que

a sociedade tem perdido seus limites. Resgatá-los implica limitar o livre passeio pelo texto ou pela vida, fazendo jus ao que há de lei simbólica na palavra "leitura", sem agir como se texto, autor e leitor não valessem nada. Isso talvez implique o trabalho de suportar a existência do outro como limite para o livre fluir da vida. (BARZOTTO, 1999, p. 17).

Vale lembrar que a forma como Barzotto (1999) e Possenti (2001) vêem a participação dos sujeitos na produção dos sentidos decorre, em certa medida, do modo como a análise do discurso mais recente concebe o sujeito. Sob essa perspectiva, "leitor e autor, como sujeitos capazes de aceder ao simbólico e na 
condição de corpo real, devem servir de limite um ao outro para se garantirem como tal" (BARZOTTO, 1999, p. 17).

\section{Sobre a questão 7 da prova discursiva de Língua Portuguesa do PS 2003 da UFG}

Na segunda etapa do processo seletivo de 2003, foram apresentadas aos candidatos três questões discursivas de língua portuguesa. A terceira e última questão desta prova, inicialmente traz um comentário sobre o gênero a que pertence o texto tomado como base para a questão: uma charge jornalística. Em seguida, esclarece-se que o humor é produzido pela combinação do texto dos balões, o desenho, além de outros recursos gráficos. Depois, chama-se a atenção dos candidatos para o fato de que as respostas devem levar em conta tanto o comentário inicial quanto a charge em si. Por fim, são apresentadas as perguntas: $a$ e $b$. Antes de comentarmos as duas perguntas, observemos a questão na íntegra:

Caixa de texto:

Na pergunta $a$, pede-se que o vestibulando explique dois pressupostos contidos na palavra depois em "Planos para depois do mandato, presidente"? e 
na $b$, os candidatos deverão explicar por que "a resposta do presidente provoca o efeito humorístico na situação apresentada". Em relação à pergunta $a$, sem haver uma definição para pressuposto, ocorre a reiteração da importância de o candidato dominar um conhecimento metalingüístico, um saber sobre a nomenclatura própria da lingüística. Pelo menos em relação a essa pergunta, talvez tivesse sido mais interessante definir o que é pressuposto do que dizer o que é charge. No entanto, para a pergunta b, foi de extrema importância e um elemento bastante positivo o comentário sobre o que é uma charge jornalística. No entanto, tão essencial quanto saber sobre a função social da charge jornalística, para a construção de uma boa resposta a essa pergunta é saber sobre as freqüentes viagens do ex-presidente Fernando Henrique Cardoso ao exterior. Assim, com essa pergunta, a banca da UFG, cumpre aquilo que propõe, quando assevera que "tem papel de destaque o contexto sócio-cultural, já que também contribui na produção dos sentidos e delimita os conhecimentos partilhados pelos interlocutores" (UNIVERSIDADE FEDERAL DE GOIÁS, 2003). O tema, o excesso de viagens ao exterior pelo ex-presidente, nesse caso, foi tomado, pela banca, como próximo do universo sócio-cultural dos vestibulandos.

\section{Análise da heterogeneidade em respostas erradas produzidas por vestibulandos}

\subsection{Da indignação social contra os políticos}

Um primeiro discurso que pode ser observado nas respostas erradas dos vestibulandos diz respeito a uma indignação social que faz ressoar velhos, mas rememorados discursos cujo veio argumentativo caminha na mesma direção, a saber, a defesa de que o governo, o presidente da república, os políticos, a administração pública, no Brasil, são incompetentes, desonestos, exploradores, irresponsáveis. Ao invés de cumprirem as promessas feitas nas campanhas, trabalhando em prol da coletividade, pelo bem do povo brasileiro, estariam se beneficiando, segundo os vestibulandos, ilicitamente, através da obtenção de privilégios para si próprios.

Recentemente, o Ibope Opinião, a pedido da revista Veja, realizou uma pesquisa cujo objetivo era descobrir o que pensam os brasileiros a respeito de seus deputados e senadores. Segundo Carneiro e Pereira (2007, p. 48), “o estudo mostra que, embora a maioria dos entrevistados considere o Congresso fundamental para a democracia, a imagem dos que hoje o habitam não poderia ser pior". De fato, os índices obtidos com a pesquisa parecem expressar, com fidelidade, o que se ouve diariamente e de maneira informal, da população brasileira sobre os políticos. O estudo revelou que, para os brasileiros, os deputados e senadores representam e defendem mais os seus próprios interesses (63\%) e os interesses dos grupos políticos (31\%) do que os interesses 
e desejos da sociedade (3\%), não sabe/ não opinou (3\%). Além disso, uma imensa parcela de brasileiros (84\%) acha que os parlamentares trabalham pouco.

No entanto, segundo a pesquisa, "mais constrangedor do que isso, só os adjetivos que os entrevistados selecionaram para classificar os seus representantes. Pela ordem: desonestos (55\%); insensíveis aos interesses da sociedade (52\%); e mentirosos (49\%)". Além desses, outros adjetivos bastante lembrados pelos entrevistados foram: oportunistas (45\%) e preguiçosos (31\%).

Nos enunciados que seguem, os vestibulandos revelam sua opinião quando defendem a idéia de que não é prioridade do governo atender os anseios da sociedade.

1) “[...] expressão despojada do então presidente, alheio a qualquer compromisso antes pregado". (PS 2003/ Questão 07b)

2) "O Brasil em sua maioria é visto com um país de políticos corruptos, de uma política não comprometida com a sociedade". (PS 2003/ Questão 07b)

3) "Porque primeiro eles depois o pais. E como dizer eu tenho o poder, por que vou preocupar com os outros". (PS 2003/ Questão 07b)

Como vemos, na opinião dos candidatos, os políticos não têm trabalhado para atender as expectativas e desejos da população. Mas os vestibulandos demonstram uma sintonia com o que pensam os brasileiros entrevistados pelo Ibope Opinião não apenas ao revelarem certa indignação com o fato dos governantes não trabalharem em prol da sociedade, como também ao se referirem aos políticos como mentirosos. Outra característica dos políticos destacada pelos candidatos é a irresponsabilidade. Vejamos os enunciados em que essas características atribuídas aos políticos aparecem:

4) “Fazendo planos para sua nova eleição, quais serão as mentiras que vão inventar para a população". (PS 2003/ Questão 07a)

5) "O Brasil ainda não encontrou seu caminho na procura de governantes sérios e responsáveis que exige a nação. Muita corrupção, impunição e hipocrisia". (PS 2003/ Questão 07b)

6) "[...] eles iludem o povo com falsas promessas. Depois de eleitos viram as costas para o povo e esquecem o que foi prometido" (PS 2003/ Questão 07a)

7) “[...] no Brasil alguns não leva a sério as administração pública”. (PS 2003/ Questão 07b)

Assim como na pesquisa apresentada pela Veja --- em que os políticos (deputados e senadores) são acusados de representar e defender mais os seus próprios interesses (63\%) --_' em alguns trechos das respostas elaboradas para a questão 07 da prova discursiva de língua portuguesa do Processo Seletivo 2003, ao enunciarem, os vestibulandos acusam o ex-presidente Fernando Henrique Cardoso de cuidar apenas de seus próprios interesses. Segundo os candidatos, o ex-presidente utiliza vias escusas para atingir esse objetivo. Explorando o povo brasileiro, o então presidente estaria aproveitando o cargo para obter privilégios e "vida boa". 
prazeres com luxo, enquanto a sociedade vive na pobreza”. (PS 2003/ Questão 07a)

"O que o presidente fará depois de cumprir o seu mandato, será viagens e descansos merecedores em paraísos fiscais". (PS 2003/ Questão 07a)

10) "[...] como se dissesse, como será maravilhoso aproveitar tudo que o cargo de presidente poderá me proporcionar por exemplo muitas viagens[ [...] enfim privilégios e vida boa". (PS 2003/ Questão 07b)

11) "O mandato do presidente foi somente para arrecadar dívidas financeiras para seu conforto e para sua viajens para o exterior". (PS 2003/ Questão 07a)

Em todos os enunciados em que o discurso sobre os políticos encontra-se materializado, atribuem-se valores negativos às ações efetivamente realizadas pelos governantes e valores positivos às que eles deixam de executar. Condenam-se as atitudes individualistas por parte daqueles que foram eleitos para trabalhar na administração pública e cobram-se soluções para graves problemas da sociedade brasileira.

Como vimos na seção anterior, a charge apresentada no comentário que inicia a questão 07 traz a caricatura do ex-presidente Fernando Henrique Cardoso. No entanto, nas respostas analisadas, há uma generalização por parte de boa parte dos vestibulandos, pois, quando se põem a escrever, às vezes nem fazem referência àquele ex-presidente, atacam o governo, os políticos de maneira ampla, generalizada e indiscriminada, como temos visto atualmente no Brasil, em decorrência, principalmente, de constantes escândalos envolvendo personalidades importantes da política, o que tem feito com que a categoria continue desacreditada pela maioria dos brasileiros, como comprovam os índices da pesquisa já citada. Perguntados sobre a porcentagem de bons deputados e senadores em atuação no Congresso Nacional hoje, quase a metade dos entrevistados (43\%) respondeu "entre 1\% e 10\%", enquanto uma parcela muito pequena (5\%) respondeu "entre 51\% e 99\%" (CARNEIRO; PEREIRA, 2007, p. 50).

Há outros enunciados que se aproximam aos apresentados acima, pois continua em debate a esfera política. Porém, nesses, os temas são a corrupção e a falta de punição aos políticos corruptos:

12) "Encher seus bolsos com dinheiro do povo e curtir o dinheiro com mais autos prazeres com luxo, enquanto a sociedade vive na pobreza". (PS 2003/ Questão 07a)

"que no brasil eles podem desfrutar sem perigo de serem descobertos por causa da corrupção sem medo. Quem tem dinheiro compra”. (PS 2003/ Questão 07b)

"Porque todo mundo interliga a política com a corrupção, é difícil acreditar nos políticos, não fazem por merecer tal crédito. E perante o povo certamente ele não falaria dos planos com 'caixa dois'. Nosso país e considerado um paraíso fiscal”. (PS 2003/ Questão 07b)

15) "O Brasil serve de piada, por que os nossos governantes se beneficiam do dinheiro público. Fazem o que eles querem e ninguém não faz nada”. (PS 2003/ Questão 07b)

16) "Por que infelizmente o nosso país é visto de maneira onde haja muita corrupção [...] e há muita facilidade para se ter uma vida fácil”. (PS 2003/ Questão 07b)

17) "Pela simples situação crítica, que deixou a economia do país, pretende continuar organizando maneira de explorar o povo brasileiro” (PS 2003/ Questão 07a)

18) "Porque o Brasil é visto pelos outros presidentes, como um país exótico e livre. A corrupção é que manda, sendo também um país de pessoas sem caráter”. (PS 2003/ Questão 07b)

19) "Por que o Brasil é visto como um país onde tudo pode antes ou depois de qualquer mandato [...]". (PS 2003/ Questão 07b)

20) "Brasil: exótico em sua: inflação, corrupção, falta de segurança pública, saneamento básico e pela marginalidade e consequentemente tráfico de drogas”. (PS 2003/ Questão 07b)

21) "O Brasil ainda não encontrou seu caminho na procura de governantes sérios e responsáveis 
que exige a nação. Muita corrupção, impunição e hipocrisia”. (PS 2003/ Questão 07b)

“[...] o nosso próprio presidente [...] quer sugar ainda muito mais do que já retirou do nosso país". (PS 2003/ Questão 07b)

23) "O presidente irá se divertir e gastar o dinheiro que conseguiu pegar dos cofres públicos". (PS 2003/ Questão 07b)

"Porque no Brasil e considerado o país do não cumprimento das leis, o país onde se vive exoticamente e não acontece nada com políticos corruptos, bandidos perigosos. Em outras palavras o país onde se faz pouco e se ganha muito". (PS 2003/ Questão 07b)

25) "O Brasil em sua maioria é visto com um país de políticos corruptos, de uma política não comprometida com a sociedade”. (PS 2003/ Questão 07b)

26) "Porque o Brasil por ser também um país exótico e também um país de muitos políticos corruptos [...]". (PS 2003/ Questão 07b)

27) “[...] depois do enriquecimento inlicido após o seu mandato”. (PS 2003/ Questão 07b)

28) “[...] não se preocupar com mais nada e com certeza com o dinheiro que faturou durante o mandato". (PS 2003/ Questão 07b)

29) "[...] quando terminar o mandato pode-se favorecer daquilo que acumulou durante o “mandato". (PS 2003/ Questão 07a)

"O que eles poderão fazer depois que saírem do governo cheios de dinheiro". (PS 2003/ Questão 07a)

31) "[...] nossos políticos geralmente quando finaliza um mandato vai descansar ou seja some [...] pois ele já enricou mesmo". (PS 2003/ Questão 07a)

32) "[...] ele quer sombra e água fresca, deitar e colocar as pernas pro ar. Ele já ganhou o dinheiro que tinha que ganhar, agora é descansar". (PS 2003/ Questão 07b)

33) “[...] Ele pode tirar férias tranqüilo ou fugir por causa de suas tramóias, fugir para bem longe sem deixar rastros". (PS 2003/ Questão 07a)

Nos enunciados acima, o Brasil é apresentado como um paraíso para quem vive de corrupção. Isso se dá, segundo os candidatos, por duas razões principais: na política do Brasil, enriquece-se com facilidade através de atividades ilícitas e não há punição para os corruptos. A história da política brasileira tem diversas páginas preenchidas por exemplos de políticos que não sofreram punição por seus atos de corrupção. Muitos desses atos, apesar de denunciados por segmentos organizados da sociedade, de amplamente noticiados pelos meios de comunicação e debatidos pela população, ficaram impunes, especialmente pela proteção dada aos políticos pela legislação brasileira, a qual possibilita uma série de expedientes aos acusados que possuem cargos políticos, facilitando-lhes, ou mesmo tornando prescindível a defesa. Em razão disso, não é tão difícil compreender a constância, nas respostas dos vestibulandos, de enunciados que versam sobre corrupção e impunidade. É outra mostra do diálogo que se estabelece entre seus discursos e os discursos que estão por aí, materializados em tantos e tantos textos, orais ou escritos, que tocam na estreita relação entre política, corrupção e impunidade no Brasil.

\subsection{Dos problemas sociais do país}

Em várias das respostas erradas analisadas, deparamo-nos com enunciados em que são tratadas questões relativas aos problemas sociais enfrentados pelos brasileiros, os quais se devem, segundo o que se pode concluir da leitura dos enunciados que seguem, ao fato do Brasil estar entre os 
34) "Porque o Brasil esta ficando longe e para trás dos outros países como Estados Unidos, Japão e outros, na sua tecnologia, no desenvolvimento social como por exemplo Educação, saúde [...]”. (PS 2003/ Questão 07b)

35) "Porque o Brasil possui uma riqueza grandiosa em todos os recursos, mas está fora do contexto de ser igual a um país que tem poucas riqueza e é mais desenvolvido economicamente do que o nosso país". (PS 2003/ Questão 07b)

36) "A charge quis passar um efeito humorístico, dizendo que o Brasil é um país atrasado". (PS 2003/ Questão 07b)

37) "Porque o Brasil apresenta problemas como por exemplo, a distância para atingir um patamar estável mundialmente e o problema da pornografia". (PS 2003/ Questão 07b)

38) "Porque apesar do Brasil ser um país exótico cheio de riquezas naturais... indústrias; comércios; o país ainda não se tornou de primeiro mundo". (PS 2003/ Questão 07b)

Nos enunciados acima, compara-se o Brasil a outros países do mundo, como Estados Unidos e Japão, transparecendo a vontade de que o Brasil venha a ser, assim como aqueles dois países citados, também um país de primeiro mundo. Os vestibulandos assumem um discurso, bastante difundido pela mídia, por exemplo, de que o Brasil está numa posição diferente, ou melhor dizendo, numa posição desfavorável em relação a países desenvolvidos, como vemos pelo uso de termos e expressões como "distante", "longe”, "para trás”, "distância”, "está fora", "ainda não se tornou”.

Nos trechos a seguir, vejamos quais, na opinião dos candidatos, são os principais problemas do Brasil ou vivenciados pelos brasileiros.

39) "Encher seus bolsos com dinheiro do povo e curtir o dinheiro com mais autos prazeres com luxo, enquanto a sociedade vive na pobreza". (PS 2003/ Questão 07a)

40) "O Brasil é um país que nele se encontra bastante diversidade de culturas e problemas sociais isso venha talvez enquandrar na palavra exótico". (PS 2003/ Questão 07b)

41) "[...] país exótico (Brasil), um país conturbado, cheio de crises, mudança de governo, economia afetada, a violência vem sendo marcante [...]”.(PS 2003/ Questão 07b)

42) "Por ser um país longe em todos os sentidos principalmente na economia e social, que apesar disso ainda tem suas belezas". (PS 2003/ Questão 07b)

43) “Combater a fome e o desemprego". (PS 2003/ Questão 07a)

44) "Porque ele vai administrar o Brasil, país que o elegeu que passa por problemas financeiro e grande desigualdade sociais". (PS 2003/ Questão 07b)

45) "Brasil: exótico em sua: inflação, corrupção, falta de segurança pública, saneamento básico e pela marginalidade e consequentemente tráfico de drogas". (PS 2003/ Questão 07b)

46) "O Brasil é um país com grande índice de pobreza e miséria em sua maioria populacional; é fato que possui inúmeras belezas, no entanto tais belezas se tornam irrizórias diante da situação econômica em que vive". (PS 2003/ Questão 07b)

47) "Porque ao referir Brasil ele presupoem que é um país que vive de pornografias, abusos sexuais entre pai e filha por exemplo, uma nação que refere as terríveis crises econômicas". (PS 2003/ Questão 07b)

48) "Porque no Brasil e considerado o país do não cumprimento das leis, o país onde se vive exoticamente e não acontece nada com políticos corruptos, bandidos perigosos. Em outras palavras o país onde se faz pouco e se ganha muito". (PS 2003/ Questão 07b)

49) "Demonstra também um ar de descrença quando se relaciona ao país Brasil deve-se pelo fato das graves crises e das grandes dívidas que o país vem acumulando". (PS 2003/ Questão 07b)

50) "Porque logo para o Brasil que encontra-se com maior descontrole inflacionário e transição presidencial". (PS 2003/ Questão 07b)

51) "Acabar com a fome de nosso pais e a mortalidade infantil". (PS 2003/ Questão 07a/)

52) "Porque o Brasil enfrenta situações desfavoráveis para um passeio no qual o país está a beira do abismo, onde há sua economia não está em alta e sim em baixa". (PS 2003/ Questão 07b)

Ao responderem à questão 7 , os vestibulandos fizeram referência aos 
mais diversos problemas do Brasil e de seu povo. Nas respostas que elaboraram, fizeram remissão a esses problemas com o uso de termos tais como: "pobreza", "desigualdades sociais", "miséria", "crises", "crises econômicas", "violência", "fome", "desemprego", "inflação", "segurança pública", "saneamento básico", "marginalidade", "tráfico de drogas", "dívida externa", "mortalidade infantil", nenhum dos quais foi tema da questão nem apareceu como tema do texto utilizado na composição da mesma.

Em 2003, como resposta ao item $b$ da questão 07, muitos foram aqueles que se puseram a falar das belezas naturais do país. Parece-nos que a presença da palavra exótico no texto funcionou como umlink, a partir do qual os vestibulandos recuperaram e fizeram funcionar discursos bem freqüentes do senso comum sobre o Brasil como um país exótico.

\subsection{Do Brasil como um país exótico}

Muitos candidatos, ao invés de responder ao que foi solicitado, puseramse a elogiar o Brasil, destacando, em particular, suas belezas naturais.

53) “O Brasil é um país com grande índice de pobreza e miséria em sua maioria populacional; é fato que possui inúmeras belezas, no entanto tais belezas se tornam irrizórias diante da situação econômica em que vive". (PS 2003/ Questão 07b)

54) "Exótico em relação as variedades que podemos encontrar nesta terra tão formosa. Por conter várias belezas naturais, uma mistura de raças e costumes". (PS 2003/ Questão 07b)

55) "Porque o Brasil é um país exótico pelo sentido que no interior do país como a floresta Amazônica é um lugar exótico onde ninguém o conheceu". (PS 2003/ Questão 07b)

56) "Porque apesar do Brasil ser um país exótico cheio de riquezas naturais... indústrias; comércios; o país ainda não se tornou de primeiro mundo". (PS 2003/ Questão 07b)

Nesses enunciados, têm lugar de destaque as "inúmeras" belezas/ riquezas naturais do país. O Brasil é retratado como uma terra formosa e exótica, cujo maior patrimônio é a floresta amazônica. Num país exótico, retratado como um paraíso de belezas naturais, seus habitantes são vistos como sendo também exóticos, diferentes, além de acolhedores, prestativos, um povo de bem com a vida.

57) “[...] visão que outros países ver o Brasil como um mundo de diverção, lazer, onde tudo se dá um jeito. Mas principalmente um pais que reina a paz, a beleza e o amor. Um povo que sorrir, mesmo quando têm que chorrar, um povo acolhedor por natureza". (PS 2003/ Questão 07b)

58) "Porque o Brasil é um país realmente exótico e distante, muito aconchegante, e as pessoas são muito prestativas como não acontece na maioria dos outros países, que são de pessoas frias e calculistas". (PS 2003/ Questão 07b)

59) "Sendo o Brasil o país com festas exóticas um povo apezar de tudo e feliz que proporciona grandes festas". (PS 2003/ Questão 07b)

Outras características que fazem do Brasil um país exótico, despertando o interesse das pessoas, são, segundo os vestibulandos, as diversões, as atrações turísticas, com destaque para o futebol, o samba e, principalmente, o carnaval. 
60) "Porque o Brasil é um país exótico devido suas festas de carnaval que leva imagens da festa para outros países". (PS 2003/ Questão 07b)

61) "[...] planos depois de mandato indica ele assistir à alguma fita com carnaval, coisas exóticas". (PS 2003/ Questão 07b)

62) "Porque o Brasil e cheio de surpresas e os turistas, quando vem para o Brasil eles sempre voltam, aqui têm lugares calmos e abadalados, [...] só não têm conflitos entre países, por isso e conhecido como um pais exótico". (PS 2003/ Questão 07b).

63) "Ele vê o Brasil como um país de mulheres bonitas temos o carnaval como uma atração". (PS 2003/ Questão 07b)

64) "Para os estrangeiro o Brasil é visto como o pais de diversões". (PS 2003/ Questão 07b)

65) "como o Brasil representa para os demais países, como para festas, carnavais, futebol, mulheres. Para eles os brasileiros vive em constante festa". (PS 2003/ Questão 07b)

66) "[...] passear, ver atrações turísticas, mulheres e distante da realidade das pessoas". (PS 2003/ Questão 07b)

67) "Por ser um país do samba, do futebol das mulatas". (PS 2003/ Questão 07b)

68) "Porque o Brasil, por ser o país do carnaval e do futebol, possa ser considerado exótico". (PS 2003/ Questão 07b)

69) “[...] visão que outros países ver o Brasil como um mundo de diverção, lazer, onde tudo se dá um jeito. Mas principalmente um pais que reina a paz, a beleza e o amor. Um povo que sorrir, mesmo quando têm que chorrar, um povo acolhedor por natureza”. (PS 2003/ Questão 07b)

70) “[...] o Brasil, devido ao carnaval, mulheres semi-nuas". (PS 2003/ Questão 07b)

71) "Sendo o Brasil o país com festas exóticas um povo apezar de tudo e feliz que proporciona grandes festas". (PS 2003/ Questão 07b)

\subsection{Da mulher brasileira e da exploração sexual das mulheres no Brasil}

Outra forma da heterogeneidade constitutiva das respostas dos candidatos que pode ser depreendida pela leitura das respostas é aquela em que a mulher brasileira é caracterizada por sua beleza, pela maneira como expõe o corpo, por sua sensualidade, erotismo. Segundo Souza (2004),

nem índia, nem negra: miscigenada. Essa é a representação da mulher brasileira bonita. As características decorrentes da miscigenação afro-índio-europeu referentes à cor da pele (morena, mulata, parda) vêm seguidas de outras que parecem naturais à mulher típica brasileira [...] sensualidade, traços marcantes. (SOUZA, 2004, p. 157-158)

A autora destaca que esse discurso sobre a mulher tem raízes assentadas no período da colonização. É um discurso nacionalista em que a mulher brasileira apresenta-se como "possuidora de grande beleza/sensualidade" (SOUZA, 2004, p. 160).

Mas não são apenas esses discursos sobre a mulher que ecoam nos dizeres dos meios de comunicação, do senso comum e nas respostas dos alunos, já que, em alguns enunciados obtidos de respostas que consideramos equivocadas, ressoam ecos de discursos sobre a exploração sexual sofrida pelas mulheres brasileiras.

72) "Porque o presidente, está pensando nas maravilhas que o sexo nos proporciona". (PS 2003/ Questão 07b)

73) "Por que, no Brasil as mulheres são muito sensuais e fazem de tudo para mostrarem sua sensualidade". (PS 2003/ Questão 07b)

74) "Por ele ser um homem do poder, respeitado querer coisas exóticas, um pouco de sacanagem". (PS 2003/ Questão 07b)

75) "Por que infelizmente o nosso país é visto de maneira onde haja [...] mulheres que se mostram [...]" (PS 2003/ Questão 07b).

76) "Porque ele escolheu o Brasil, por o lugar de mulheres bonitas e exóticas". (PS 2003/ 
Questão 07b)

77) "Ele vê o Brasil como um país de mulheres bonitas temos o carnaval como uma atração". (PS 2003/ Questão 07b)

78) "Brasil toma uma segunda opição, pois para se divertir principalmente com as lindas morenas". (PS 2003/ Questão 07a)

79) "Porque para muitos extrangeiros o Brasil e visto como o pais do futebol e do carnaval e mulheres semi-nuas". (PS 2003/ Questão 07b)

80) "Porque, o Brasil é considerado um país erótico, por causa das mulheres peladas que saem em Revistas como Playboy e também em internet, pelo mundo inteiro então nosso país e conhecido como País Erótico e também vulgar". (PS 2003/ Questão 07b)

81) "O Brasil não tem fronteiras é livre, e cheio de mulheres bonitas, muitas praias e que os brasileiros são fáceis de dominar". ((PS 2003/ Questão 07b)

82) "O Brasil e um pais exotico o pais do carnaval [...] onde há também as mulheres mais bonitas". (PS 2003/ Questão 07b)

83) “[...] pelo presidente considerar o Brasil um país exótico que tem como imagem mulheres bonitas, diversão e pouco trabalho". (PS 2003/ Questão 07b)

84) "Porque o Brasil apresenta problemas como por exemplo, a distância para atingir um patamar estável mundialmente e o problema da pornografia". (PS 2003/ Questão 07b)

85) “[...] passear, ver atrações turísticas, mulheres e distante da realidade das pessoas". (PS 2003/ Questão 07b)

86) “Por ser um país do samba, do futebol das mulatas". (PS 2003/ Questão 07b)

87) "Porque ao referir Brasil ele presupoem que é um país que vive de pornografias, abusos sexuais entre pai e filha por exemplo, uma nação que refere as terríveis crises econômicas". (PS 2003/ Questão 07b)

88) "É porque no nosso Brasil esta avendo muito protituição, quando ele fala exoticos ele quis dizer isto a muitos turistas vindo de fora só para prostituir as dimenores". (PS 2003/ Questão 07b)

89) “[...] o Brasil, devido ao carnaval, mulheres semi-nuas”. (PS 2003/ Questão 07b)

90) “[...] Brasil e é o país conhecido exótico pelas as mulheres que o Brasil possui”. (PS 2003/ Questão 07b)

\section{Considerações finais}

Pela análise do corpus, podemos concluir que os vestibulandos produzem enunciados em que, ao invés de focalizarem as perguntas, focalizam tão somente os temas dos textos ou, para sermos mais exatos, temas que os temas dos textos dados sugerem. Assim, enquanto o foco da questão é um, o apresentado nas respostas dos candidatos é outro.

Ao perceberem que a questão traz um texto que faz referência às ações de um político (como é o caso da questão 7 do Processo Seletivo 2003), os alunos resgatam o que já ouviram e/ou leram sobre o assunto. Assim, apresentam uma imagem dos políticos como sendo corruptos, em decorrência, principalmente, da falta de punição, construindo para si a imagem de um sujeito bem-informado, indignado contra a impunidade e, principalmente, engajado, consciente de seu papel na sociedade. Além disso, a presença da palavra exótico no texto parece ter funcionado, para alguns candidatos, como umlink, a partir do qual recuperam e fazem funcionar discursos bem freqüentes sobre o Brasil como um país exótico, possibilitando-lhes, inclusive, resgatar discursos em que a mulher brasileira é caracterizada por sua beleza, por sua sensualidade, erotismo, pela maneira como expõe o corpo e pela exploração de que, muitas vezes, é vítima.

Desta forma, em razão de leituras erradas realizadas, nas respostas em análise, os candidatos tematizam sobre assuntos à revelia daqueles que se 
apresentam na questão proposta e no texto que a compõe. O que parece ocorrer é que os candidatos põem-se a desenvolver o tema em questão, melhor dizendo, aquele que consideram em pauta, através da referência a discursos que, possivelmente, vêem como sendo do agrado de quem lerá suas respostas em razão de sua larga circulação no seio social.

\section{Referências bibliográficas}

AUTHIER-REVUZ, J. Heterogeneidade (s) enunciativa (s). Cadernos de estudos lingüísticos, Campinas: IEL/ UNICAMP, 19, p. 25-42. 1990.

. Heterogeneidade mostrada e heterogeneidade constitutiva: elementos para uma abordagem do outro no discurso. In: . Entre a transparência e a opacidade: um estudo enunciativo do sentido. Porto Alegre: EDIPUCRS, 2004.

BAKHTIN, M. Marxismo e filosofia da linguagem. São Paulo: Hucitec, 1995.

Estética da criação verbal. São Paulo: Martins Fontes, 2000.

BARZOTTO, V. H. Prefácio. In:

(Org.). Estado de leitura. Campinas:

Mercado de Letras: ALB, 1999.

. Limites na leitura: o texto e seus suportes. In: GREGOLIN, M. do R. V. Análise do discurso: entornos do sentido. Araraquara: Laboratório Editorial; São Paulo: Cultura acadêmica, 2001.

BRAIT, B. Alteridade, dialogismo, heterogeneidade: nem sempre o outro é o mesmo. In:__(Org.). Estudos enunciativos no Brasil: histórias e perspectivas. Campinas: Pontes; São Paulo: Fapesp, 2001.

BRANDÃO, H. N. Introdução à análise do discurso. Campinas: Editora da UNICAMP, 1997.

CARNEIRO, M.; PEREIRA, C. “Desonestos, insensíveis e mentirosos". Veja, São Paulo, ano 40, n. 4, p. 48-54, 31 jan. 2007.

FIORIN, J. L. O romance e a simulação do funcionamento real do discurso. In: BRAIT, B. (Org). Bakhtin, dialogismo e construção do sentido. São Paulo: Editora da UNICAMP, 1997.

MAINGUENEAU, D. Gênese dos discursos. Curitiba: Criar edições, 2005.

POSSENTI, S. Apresentação da análise do discurso. Campinas: IEL/UNICAMP, 1985. Mimeografado.

. A leitura errada existe. In: BARZOTTO, V. H. (Org.). Estado de

leitura. Campinas: Mercado de Letras: ALB, 1999.

. Existe a leitura errada? Entrevista concedida a CARVALHO, J. M. T. de; MARINHO, M. Presença pedagógica, v. 7, n. 40, p. 5-18, 2001. 
. Observações sobre interdiscurso. Campinas: IEL/UNICAMP, [2003?]. Mimeografado.

SOUZA, A. de F. da C. O percurso dos sentidos sobre a beleza através dos séculos - uma análise discursiva. 2004. 221 f. Dissertação (Mestrado em Lingüística)-Instituto de Ciências da Linguagem, Universidade Estadual de Campinas, Campinas, 2004. Disponível em: $<$ http://libdigi.unicampbr/document $\angle$ ?code $=$ vtls000334513.htm $>$. Acesso em: 22 dezembro 2006.

UNIVERSIDADE FEDERAL DE GOIÁS. Centro de seleção. Manual do candidato: processo seletivo 2003. Goiânia, 2003. 